\title{
¿Qué esperan los pacientes de su médico en el futuro? Reflexiones sobre nuestro sistema sanitario
}

\author{
Juan Siso Martín \\ Subdirector General del Defensor del Paciente de la Comunidad de Madrid
}

Todos tenemos derecho a la protección de la salud, según el artículo 43 de nuestra Constitución. En algún lugar del propio texto fundamental se menciona, sin embargo, el derecho a la salud, imposible de garantizar por cualquier estado, evidentemente, para sus ciudadanos y que en caso de pretender su cumplimiento haría destinatarios de las demandas no a los poderes públicos, sino al coronavirus o al estafilococo aúreo, que nos hubieran arrebatado la salud. De salud y de derecho vengo a hablarles, para centrarlo en la relación del paciente con el médico. Veamos:

Mi generación, cuando éramos niños, coleccionábamos un álbum de cromos que se llamaba algo así como El Futuro en el año 2000. Mostraba a los asombrados ojos infantiles que se asomaban a sus cromos una ciudad con el cielo cuajado de platillos voladores y robots caminando por las calles. Llegó, y pasó, el año 2000 y esa escena no la hemos vivido. Hemos asistido, sin embargo, a un aspecto del progreso que nadie podíamos entonces sospechar. Vivimos la era de las comunicaciones, estamos comenzando más bien esta era, de la que nos encontramos, con seguridad, en su edad de piedra. ¿Quién podía imaginar que íbamos a poder hablar, en medio del campo o desde una playa, con el otro lado del mundo? ¿Quién podría haber sospechado que lo haríamos a través de un artilugio cada vez más pequeño y polivalente?. Lo llamamos móvil, ifaltaría mas!. A quien se le podría haber ocurrido que aquel diccionario Espasa, de innumerables tomos, y al que considerábamos el oráculo del saber, el no va más de la cultura, se convertiría en una insignificancia al lado de la información que podemos obtener en segundos, sobre los asuntos más insospechados, a través de la red de Internet?

Internet, es preciso reconocer, hasta para quien sea, como yo mismo hasta no hace demasiado tiempo, objetor de conciencia informático, es el motor de la economía actual. Su poder, afirma Alvaro Lista, radica en que es global, resuelve necesidades de comunicación y conocimiento a costos mínimos y añade valor con todo ello a nuestras acciones. Es evidente el hecho de que las empresas llevan tiempo migrando sus procesos a la red. El mundo de la salud no ha podido quedar fuera de esta auténtica revolución cultural. La cuestión es si dentro de este ámbito, el elemento más trascendente, la relación médico paciente, podrá llegar a realizarse satisfactoriamente.

Es incuestionable que vivimos en la sociedad de la información y ésta es la plataforma de acceso al conocimiento. El paciente está cada día más informado y aunque la situación clínica la controla, lógicamente, el médico es indiscutible que se ha acortado, con carácter general, la distancia en el conocimiento entre ambas partes de la relación asistencial.

Es, precisamente, de esta relación y de su visión por parte de los pacientes de lo que les quiero hablar en mi intervención. De cómo es percibida actualmente y de cuales son las exigencias de futuro que se plantean ya por los usuarios de la Sanidad.

Voy a referirme a las demandas hacia el profesional, dejando a un lado aquellas otras que se dirigen a los financiadores y dispensadores de las prestaciones en asuntos como el elenco prestacional o la propia sostenibilidad del Sistema.

\section{SITUACIÓN ACTUAL}

Los requerimientos actuales de los usuarios de la Sanidad y de los pacientes hacia el Sistema son muchos, por razones del tiempo disponible voy a ceñirme solamente, y a modo de ejemplo a tres de ellos:

La información. En este momento que nos ha tocado vivir, en el que hay más información y conocimiento que nunca, en ambas partes de la relación asistencial, se da la paradoja de que persiste una comunicación insuficiente del paciente con los profesionales sanitarios. Las causas son unas veces estructurales, del sistema, como el escaso tiempo a dedicar a cada paciente y en otras ocasiones de origen personal, conductuales del profesional. Se sobreutiliza el lenguaje médico, muchas veces, hasta convertirlo en una barrera relacional. Se cae en la tentación o en el rutinario descuido de su 
abuso cuantitativo y de su carácter críptico en lo cualitativo. El uso del lenguaje técnico aporta indudablemente precisión y concreción, pero su abuso en el diálogo con el paciente puede ser perjudicial, en lugar de ventajoso. Entre profesionales es perfectamente inteligible EPOC , la mención de un cerclaje o de determinada posología medicamentosa. Incluso en el texto de los informes clínicos pueden contenerse elipsis como no midriasis, o no disnea. Hasta se permiten ciertas alegorías pseudopoéticas como aquella, difícil de olvidar, de que el cáncer de recto navega con la bandera de las hemorroides. Cualquiera de esos usos es absolutamente inadecuado dirigido a un paciente, mostrado en la forma expuesta e incluso en otra más liviana, como le voy a poner un tratamiento analgésico. Siendo esta expresión inteligible hoy día para la práctica totalidad de la población pude exceder, sin embargo, a ciertos destinatarios ubicados en los niveles más básicos de la cultura.

El paciente confía en que el médico orienta la actuación clínica en provecho de aquel, da por supuesto que se busca el beneficio sanitario, pero precisa que se lo expliquen y necesita entender su compromiso vital en tan delicado asunto como la salud.

La tecnología. Se incorpora ésta al uso de la práctica médica a finales del Siglo XIX, con la aparición de la radiología en 1895 y más adelante, en 1902, con el descubrimiento de la máquina electrocardiográfica, adoptadas ambas, pronto, de manera masiva. Décadas después llegaría una gran novedad, procedente del mundo de los negocios, la telemática.

El hecho es que la Medicina, se dice, ha avanzado más en los últimos 30 años que en los 30 siglos anteriores. En la memoria de todos quienes llevamos unas décadas en el mundo sanitario está el hecho de que existían unos servicios clínicos que se llamaron de Radiología y ahora reciben el nombre de Diagnóstico por Imagen. Obedece a que aquello que era el medio único de diagnóstico por imagen (la radiología) ha sido complementado por muchos más: TAC, RNM, Ecografía, Ecocardiografía, Mamografía, PET...

Con ese arsenal de ingeniería médica el paciente concibe la Medicina como una ciencia omnipotente y demanda la aplicación de unos medios en los que confía tanto que, si no obtiene el provecho que busca, deduce que no se aplicaron correctamente. Exige, por otra parte, su utilización en algunas ocasiones, sin tener en cuanta su coste y su escasez, pudiendo comprometer, bajo criterios de equidad y justicia, los recursos del sistema.

Hay que tener presente que a la par que se desarrolla tecnológicamente le ejercicio de la Medicina, viene ensanchándose la cultura sanitaria y se demandan prestaciones, unas veces nuevas (reproducción asistida, cirugía transexual) y otras con mayor intensidad (mamografías preventivas hasta edades más avanzadas).

La inmediatez. Vivimos un tiempo en que todo lo queremos ahora y si además se trata de salud, imagínense... El hecho es que el paciente necesita que le hagan con prontitud su diagnóstico y que acometan sin demora la acción terapéutica subsiguiente. El problema es que se dan unas condiciones muy difíciles para ello: recursos limitados, asistencia universal y gratuita. Estamos en presencia de uno de los problemas más difíciles para los gestores sanitarios, a la par que uno de los asuntos de mayor interés para los usuarios. De ahí que se convierta su pronta gestión en un objetivo sanitario básico para los gobernantes.

\section{EXIGENCIAS DE FUTURO}

Estamos asistiendo a un cambio sustancial en la orientación de las reclamaciones de los pacientes. En la Oficina del Defensor del Paciente elaboramos el pasado año el documento: Declaración de los Pacientes de Madrid, comprensivo de la Carta de Derechos y Deberes de los Pacientes. Este documento fue el fruto de numerosas reuniones y mesas de trabajo, que tuve la satisfacción de dirigir, con asociaciones y federaciones de pacientes, de las cuales se extrajeron conclusiones para incorporarlas al citado documento. Su análisis muestra magníficamente la orientación de las demandas de los pacientes para la Sanidad del futuro.

Intimidad. El paciente ha de hacer, necesariamente, una cesión de ella para posibilitar la actuación clínica; pero exige cada vez más que sea utilizada sólo lo imprescindible. Examinar las partes de su cuerpo que sea preciso, pero sólo esas y sin presencias de personas innecesarias para la asistencia.

Confidencialidad. De igual manera el Sistema necesita disponer de información reservada de los pacientes, para su actuación. El paciente pone énfasis en que se preserve absolutamente y en la obligación de confidencialidad del Sistema sanitario sobre aquellos datos sensibles que posee de los pacientes.

Acceso a la documentación clínica. El ciudadano se siente protagonista de la información que el 
Sistema tiene de él. Las nuevas normas (Ley 15/1999, de Protección de Datos y 41/2002, Básica de autonomía del Paciente) confirman y afianzan las nuevas tesis de que la información sanitaria se encuentra a disposición de sus titulares y otras personas autorizadas. Se superan tiempos de hermetismo, cuando no de orientación defensiva de las negativas de acceso a la documentación, señaladamente de la Historia Clínica.

Autonomía en las decisiones. Bajo la concepción de ese protagonismo antes mencionado, el paciente quiere tomar sus propias decisiones, solicitando los medios para ello. Estas decisiones pueden llevarse a cabo para actuaciones sanitarias durante su vida (terreno natural del Consentimiento Informado) o plantearse en supuestos próximos a la muerte, como es la reciente aportación normativa de las instrucciones previas o testamento vital.

Atención especial a colectivos sensibles. Es creciente la concienciación social sobre la necesidad de cuidar especialmente el trato hacia los ancianos, discapacitados o menores. La situación de indefensión de cualquier paciente ante los profesionales sanitarios es aún mayor para estas personas. Permitir, junto con ellos, la presencia de sus valedores cuando sea necesario es ya una demanda social unánime.

Inquietan menos otras cuestiones muy actuales y sobre las cuales aún no se ha formado opinión social al respecto, señaladamente en el resbaladizo campo de la genética, como la utilización de células madre, la clonación terapéutica, la concepción de niños medicamento, gestación mediante contrato, selección de sexo preimplantacional o el descubrimiento de código genético.

\section{REFLEXIÓN FINAL: ¿ES BENEFICIOSO QUE EL PACIENTE RECLAME?}

Premisa: Una reclamación es una fuente de información, que nos muestra los puntos calientes del sistema y algunas deficiencias que podemos no conocer. En el primer caso detectamos su importancia, en el segundo su existencia misma.

La peligrosa cadena del paciente tranquilo: Cuando un usuario resulta insatisfecho puede actuar de alguna de estas dos formas.

1 de cada 10 se queja, 9 de cada 10 se van sin quejarse y no vuelven. Estos son peligrosos porque: no nos permiten detectar nuestros fallos, transmiten a los demás una imagen negativa y es la peligrosísima antipublicidad sumergida.

Apología del buen servicio: La diferencia entre un buen servicio y un servicio excelente es cuestión de milímetros y un servicio excelente se recuerda siempre. En el servicio público hay obligatoriedad en su utilización, este hecho aumenta la responsabilidad del servidor público. 